Int. J. Electrochem. Sci., 11 (2016) 10029 - 10052

\title{
Microstructure and Corrosion Behaviour of Carbon Steel and Ferritic and Austenitic Stainless Steels in NaCl Solutions and the Effect of $\boldsymbol{p}$-Nitrophenyl Phosphate Disodium Salt
}

\author{
Mohammed A. Amin ${ }^{1,2, *}$, Murat Saracoglu ${ }^{3}$, N. El-Bagoury ${ }^{1,4}$, T. Sharshar ${ }^{5,6}$, Mohamed M. Ibrahim ${ }^{1,7}$, \\ Joanna Wysocka ${ }^{8}$,Stefan Krakowiak ${ }^{8}$, Jacek Ryl $l^{8}$ \\ ${ }^{1}$ Materials Science and Engineering group, Chemistry Department, Faculty of Science, Taif \\ University, P.O. Box 888, Haweiyah, Saudi Arabia \\ ${ }^{2}$ Chemistry Department, Faculty of Science, Ain Shams University, P.O. Box 11566, Abbassia, Cairo, \\ Egypt \\ ${ }^{3}$ Faculty of Education, Erciyes University, 38039 Kayseri, Turkey \\ ${ }^{4}$ Casting Technology Lab., Manufacturing Technology Dept., Central Metallurgical Research and \\ Development Institute, CMRDI, P. O. Box 87 Helwan, Cairo, Egypt \\ ${ }^{5}$ Physics Department, Faculty of Science, Taif University, P.O. Box 888, Al-Hawiah, Taif 21974, \\ Saudi Arabia \\ ${ }^{6}$ Physics Department, Faculty of Science, Kafrelsheikh University, Kafr El-Sheikh 33516, Egypt \\ ${ }^{7}$ Chemistry Department, Faculty of Science, Kafrelsheikh University, Kafr El-Sheikh 33516, Egypt \\ ${ }^{8}$ Department of Electrochemistry, Corrosion and Materials Engineering, Faculty of Chemistry, Gdańsk \\ University of Technology, Narutowicza Str. 11/12, 80-233 Gdańsk, Poland \\ *E-mail: maaismail@yahoo.com
}

doi: $10.20964 / 2016.12 .17$

Received: 15 July 2016 / Accepted: 23 September 2016 / Published: 10 November 2016

The microstructure and corrosion behavior of carbon steel (CSA516) and ferritic (SS410) and austenitic (SS304L) stainless steels were studied and compared. Corrosion tests were carried out in 0.5 $\mathrm{M} \mathrm{NaCl}$ solutions. Rates of corrosion were monitored based on weight loss, Tafel extrapolation and linear polarization resistance (LPR) methods. Rates of corrosion were ranked following the order: CSA516 > SS410 > SS304L. The impact of $p$-Nitrophenyl phosphate disodium salt (NPP) on the corrosion rate of CSA516 was also studied using Tafel polarization and LPR measurements. Optical microscopy (OM), scanning electron microscopy (SEM/EDX), and X-ray photoelectron spectroscopy (XPS) were employed to assess the chemical compositions and morphologies of the corroded and inhibited surfaces. FT-IR analyses were also performed to assess the functional groups of the inhibited sample in a comparison with NPP itself. XPS and FT-IR studies revealed the presence of phosphate groups originating from tested inhibitor, thus proving formation of the protective layer on the steel surface. The microstructural and defect investigations of as-polished, corroded, and inhibited CSA516 samples were also carried out using positron annihilation lifetime (PAL) and positron annihilation Doppler broadening (PADB) techniques. Experimental findings revealed that NPP acted as an efficient 
mixed-type inhibitor with anodic predominance. It reached about $97 \%$ inhibition efficiency at a low concentration of $0.02 \mathrm{M}$.

Keywords: Monitoring rates of corrosion; Corrosion control; Steel and stainless steel materials; Tafel extrapolation method; Linear polarization resistance method; Positron annihilation spectroscopy

\section{$\underline{\text { FULL TEXT }}$}

(C) 2016 The Authors. Published by ESG (www.electrochemsci.org). This article is an open access article distributed under the terms and conditions of the Creative Commons Attribution license (http://creativecommons.org/licenses/by/4.0/). 